\title{
Emotional Intelligence and Employee Intention to Retain: A Case Study of a Organization in Fast Moving Consumer Goods in Sri Lanka
}

\author{
P.A.S. Fernando*, Prof. Prasadiniu Gamage \\ Department of Human Resource Management, Faculty of Commerce and Management Studies, University of \\ Kelaniya, Sri Lanka
}

*Corresponding Author: P.A.S. Fernando, Department of Human Resource Management, Faculty of Commerce and Management Studies, University of Kelaniya, Sri Lanka

\begin{abstract}
The purpose of this study is to examine the relationship between the Emotional Intelligence (EI) of managers and retention intention of their direct reports. The findings are discussed in terms of a business case and it was conducted in one of the leading organization in the field of Fast Moving Consumer Goods in Sri Lanka, targeting the head office staff employees. The employees were given questionnaires to complete in order to assess their retention intention and to rate the level of EI of their leaders as how they perceived it. Correlation analyses were then performed with the data.

The statistical results showed that the leaders' EI has a significantly moderate and positive impact on the retention intention of their direct reports. The results of this study contribute to current insights about the interrelationships on managers' EI and employee outcomes, showing the importance of improving EI within organizational leaders.
\end{abstract}

Keywords: Emotional Intelligence, Intention on retain

\section{INTRODUCTION}

The heart of every organization is its people, why because the success or failure of an organization is largely dependent on the caliber of the people working therein. Getting the right employees into an organization may be challenging, however, the retention of employees has become much more challenging to organizations (Chitra, 2013). Retention of employees has become one of the major concerns for organizations because of the high rate of employee turnover in organizations. Employees leaving an organization might be replaced physically by recruiting another; however their skills and tacit knowledge cannot be exactly replaced by the person replacing them, as each individual possesses a different and a unique set of skills and experience. Therefore, staff retention takes a higher concentration of the management since employee efficiency and their talent determines the place and the future survival of a company.

Employee retention is not influenced by a single factor, but there are hosts of factors which are responsible for retaining employees in an organization. Out of these bulk of reasons, the role of leaders in employee retention has become critical since literature indicates that staffs leave leaders and not organization (Beardwell, Holden, \& Claydon, 2007). Therefore organizations cannot leave the responsibility of keeping well performing employees wholly into the hands of the Human Resource Department any longer. Similarly the leaders have a big responsibility to properly deal with and properly handle their staff in order to maintain and enhance the staff retentions. They should possess with suitable qualities and characteristics to induce a willingness within their subordinates to stay longer with the organization. Prior research has recognized the leader's vital contribution in influencing an employee's intention to stay on the job (Vecchio, 1985). Accordingly, one of the most vital relationships in a business context is the link between the employees and their immediate boss/supervisor or the leader to whom the employee has to report. These leaders have the greatest influence in building this relationship. The quality of relationship an employee has with his or her immediate managers elongates employee stay in an organization (Ferreira, 2007 as cited in Michael, 2008). 
Retention of employees is not a matter that can be dealt by the reports or records, it is purely depends on how they understand individual concerns and how they react on them. Further it is becoming very tough as well as difficult for the employers to satisfy and retain them since there are ample of opportunities available for the skilled and talented human resources whenever they're looking for. Therefore every organization tries its level best to provide enough facilities to their employees to make them happy and retain them. It is not an easy task to get to know, what is going on in the human mind and what are they actually need or expect from the employer time to time(Das \& Baruah, 2013).Therefore the leaders are expected to have emotional intelligence (EI) traits that allow them to better understand themselves and their team members as well. Goleman et el., (2004), while expounding their theory of "primal leadership", remarked that: Great leadership works through the emotions . . . No matter what leaders set out to do - their success depends on how they do it . . if leaders fail in this primal task of driving emotions in the right direction nothing they do will work as well as it could or should (p. 3). This clearly implies the importance having EI in becoming a good leader. Further leadership is fundamentally declared as an emotion-management process wherein leaders manage their own emotions and those of their followers (Yukl, 2002).Thus it can be finally concluded that different employees have different expectations, therefore it's inevitable to have good leaders who can understand the needs and behavior of each employee and mould their leadership style accordingly in order to make them happy and to retain them.

In the olden days someone was regarded as intelligent if he or she could "read, write and do arithmetic". Now we know it is surely not the case. People pass exams but fail in life. They strive for results but struggle in their relationships. The original Latin root of intelligence means 'to understand'. It is in fact an umbrella term that encompasses many abilities of the brain. One such key type has emerged prominently as Emotional Intelligence (Daily FT, 2018).

Two psychologists Peter Salovey and John Mayer first introduced EI in 1990 and they defined EI as "a form of intelligence that involves the ability to monitor one's own and other's thinking and actions" (Carmeli, 2003). The soundest approach to emotional intelligence is the abilities model also suggested by Salovey, Mayer and colleagues (Salovey \& Mayer, Emotional intelligence, 2004; Caruso, Mayer, \& Salovey, 2002). The abilities model consists of four general emotional abilities:

- Identifying emotions, which involves the ability to recognize emotions in oneself and others, as well as the ability to express emotions;

- Using emotions to facilitate thinking, which involves using emotions to improving thinking processes and harness the power of positive moods;

- Understanding emotions, including the complexities and subtleties of emotions as well as their interrelationships; and

- Managing emotions, which involves skills in regulating and controlling felt emotions in a positive fashion.

In 1995, Daniel Goleman opened the eyes of the world about the concept of EI and he defined EI under the trait perspectives or mixed model as "one's ability to motivate oneself and persist in the face of frustration; to control impulses and delay gratification; to regulate one's moods and keep distress from swamping the ability to think; to empathize and to hope. EI can lead to enhanced functioning in a variety of aspects of life such as achievement and close relationships (Goleman, 1995). If you have a high level of emotional intelligence you'll find it easier to build stronger relationships, create success at work, and achieve your career and personal goals. Emotional intelligence can help you navigate the social complexities of the workplace, lead and motivate others, and excel in your career. In fact, when it comes to gauging job candidates, many companies now view emotional intelligence as being as important as technical ability and require EI testing before hiring. Therefore this article would be much useful to individuals in order to have a proper understand about emotions plus the value of improving it for their personal benefit.

Literature suggests that the leader's EI has a great impact on employees' outcomes such as their job satisfaction, organizational commitment and job stress. Along with that literature support the current study aims to investigate the relationship between leader's emotional intelligence and the employee retention. Through the literature review it was able to found that a great deal of researches have been 
carried out on EI, transformational leadership style and effects on individual employees. Still there is limited literature that shows the relationship between the two variables of leader's EI and their subordinates' retention intention in the context of Sri Lanka. Therefore the researcher decides to carry out a survey investigation to explore the relationship between these two variables. The results of this study will contribute to the current insights about the interrelationships on managers' EI, leadership style and employee outcomes, showing and the power of managers' EI in order to produce positive employee behavior. And also to get realized about the significant impact it would have on talent retention. These findings will endorse the validity of incorporating EI interventions alongside the recruitment and selection process and the training and development process of managerial personnel.

\section{RESEARCH CONTEXT}

In order to carry out this empirical research study that looked at how the employee retention intention got affected or got an impact particularly from their immediate boss's emotional intelligence behavior, the researcher decides to carry out a survey investigation selecting a particular organization in Sri Lanka by targeting its employees. For that purpose the researcher has selected a Sri Lankan well established Fast Moving Consumer Goods (FMCG) manufacturing and distribution company namely, E B Creasy \& Company PLC (EBC)to conduct the study based on both executive and non-executive employees in the head office premises. EBC has developed their operations over nine business sectors since 1878 and the Company is among the pioneers of The Ceylon Chamber of Commerce having joined in 1890, while Darley Butler - a wholly-owned subsidiary - enjoys the distinction of being one of the three oldest members since 1852. Over the years E. B. Creasy has expanded by organic growth as well as by strategic acquisitions and now constitutes a diversified Group spanning a wide spectrum of activities ranging from import, export, distribution and freight forwarding to formulating trading in chemicals and hoteliering. Therefore the research findings were discussed in terms of a business case targeting this particular organization in Sri Lanka.

\section{Problem Statement}

One of the most critical issues that almost every organization are struggling with and are lookout for solutions is employee retention. Organizations are trying out for many different methods for attracting efficient people and use various tactics to retain them. Currently the literature has revealed that leaders and their skills is a key to answer why people stay or what usually drives them away from a company. Thus now the companies' number one priority is to look at their management and more focus is made on understanding their characteristics and behavior of the leaders prevailing in the company.

Although there has been a substantial amount of research on leadership and emotional intelligence as separate constructs, limited research has been conducted on the relationship and/or linkage between EI of leaders and the impact that can have on employee retention intention. While there have been a few studies in academia, to our knowledge there is only one published research article in measuring on the possible association between manager rated EI and subordinate self-rated employee engagement combining with talent retention which was conducted using samples from three large companies in USA, India and Australia.

Having considered the situation discussed above, the current researcher identified the research gap. This is one of the most critical issues that almost every organization are struggling with and lookout for solutions while many have lack of knowledge about the real importance of a leaders' EI could do with their employees. So that current researcher identified that empirical gap and at the same time there is no any research conducted under the current issue in Sri Lankan context. Accordingly the current researcher will try to test it within the Sri Lankan context.

Hence the research problem addressed in this study can be derived as: To assess the impact of the leaders' perceived emotional intelligence on employee retention intention of the head office staff employees in a leading organization in the field of FMCG.

\section{OBJECTIVES OF THE STUDY}

\subsection{General Objective}

The main objective of this study is to examine the interrelated association between the managers' EI involved with their leadership behavior and employees' retention intention. Further to measure the impact of leaders' EI could have on their subordinates' retention intention. 


\subsection{Specific Objective}

- To identify the extent to which the leader's emotionally intelligent role influences to create positive employee attitudes and behavior.

- To identify the significance of improving EI within organizational leaders

- To examine whether the leaders' emotional intelligence and their behavior affected to determine whether the employees will stay longer or quit.

- To determine recommendations for organizations to be applied in order to improve the leadership styles of existing leaders.

\section{LITERATURE REVIEW}

"People join companies and leave managers," Marcus Buckingham, senior managing consultant at Gallup -Global performance-management consulting company. Research indicates that EI in the leadership of an organization directly affects the retention of quality employees and overall productivity. A study by Gallup Organization reveals that most workers rate having a caring boss is even higher than money or fringe benefits. In interviews with two million employees at 700 companies, Gallup found that the length of time employees stay at companies and their level of productivity are directly related to the relationship they have with their immediate supervisor (Expedite, Human Resources).

\subsection{Employee Retention Intention}

In simply employee retention intention can be defined as, employees' intention to stay in the present employment relationship with their current employer on long term basis. Similarly Hewitt (2004) reflects that "Intention to stay mirrors the employee's level of commitment to his organization and the willingness to remain employed". However this is the converse of the turnover intention or intention to quit (Kim, Price, Mueller, \& Watson, 1996). According to Mobley(1982);Steers \& Mowdays(1981) intention to stay was significantly negatively correlated with turnover. Since intention to stay was referred to as employees' willingness to stay with an organization andit consistently demonstrated a stronger relationship with turnover than did other turnover precursors (Tett \& Meyer, 1993).

Retaining employees has become much important in today's competitive business context. Employees are considered as the life blood of an organization since they can make or even can break an organization. Therefore retaining them will help for the growth and survival of an organization in long run. In the study of Fitz-enz (1997) indicated that when direct and indirect costs are combined, the total turnover cost of an exempt employee ranges from a minimum of one year's pay and benefits to a maximum of two years' pay and benefits. Thus, there is significant economic impact when an organization loses any of its critical employees, especially given the knowledge that is lost with the employee's departure. Fitz-enz (1990) The Retention factor can be divided into three broad dimensions as social, mental and physical.

- The mental dimension of retention consist of work characteristics, employees always prefer flexible work tasks where they can use their knowledge and see the results of their efforts which, in turn, helps in retaining the valuable resources.

- The social dimension consists of the contacts that the employees have with other people, both internal and external.

- The physical dimension consists of working environment and pay.

Moreover, Goleman (1998b) suggests that emotional intelligence plays a substantial role in leadership. A leaders' effectiveness will depend on how well they can manage themselves and how well they are able to manage or deal with others. Studies have already disclosed that successful leadership is not about intellectual ability or technical expertise; rather it is about personal characteristics and human qualities that include empathy and compassion, flexibility and influence. It is these personal characteristics and human qualities that are encompassed in the definition of emotional intelligence. Therefore, understanding the effects of a leader's EI for a business organization and the potential impact it has on subordinates' retention intention is explored in this study. 


\subsection{Leaders' Emotional Intelligence}

EI is one of the strongest drivers of leadership and excellence. People often use to undervalue the importance of feelings and emotional processes in a workplace, rather than in their personal life. Yet it's essential to remember that our professional relationships with clients, colleagues or with our team members are largely influenced by the persons' overall emotional state and their awareness of it. So that in order to develop solid, trusting relationships in the business arena, it is essential to increase an effective use of EI.

In simple terms EI is the ability to understand and manage your own emotions, and those of the people around you. People with a high degree of emotional intelligence know what they're feeling, what their emotions mean, and how these emotions can affect other people (Expedite, Human Resources). When it comes to leaders in a workplace, might be a manager or a supervisor, having EI is indispensable for them to be success. EI is that much essential for leaders because it is clear to anybody that, who is more likely to succeed, whether a leader who shouts at his team when he's under stress or a leader who stays in control and calmly assesses the situation. Definitely the answer would be the second person since no one likes to work under a querulous and fussy leader.

Daniel Feldman explains in his Handbook of Emotionally Intelligent Leadership, "Effective leaders use their personal power to influence others, as much as their position power. Position power is based on the authority from the formal position that one holds. Personal power is based upon one's relationship with others. Personal power is built through the use of the skills of emotional intelligence."

Even though there are a lot of definitions of EI, the current study has been constructed on the basis of Salovey \& Mayer's(1990) and Goleman's (1998) approaches to EI. Goleman (1998, p.317) defines the EI as "The capacity for recognizing our own feelings and those of others, for motivating ourselves and for managing emotions well in ourselves and in our relationships." Similarly Peter Salovey and John D. Mayer (1990, p. 189) define EI as "The ability to monitor one's own and others' feelings and emotions, to discriminate among them and to use this information to guide one's thinking and actions." Further it describes that EI does not include the general sense of self and appraisal of others. Rather it focuses on the processes described specifically above, that is, the recognition and use of one's own and others' emotional states to solve problems and regulate behavior. Moreover they have operationalized portions of EI and propose that mental processes included with a) appraising and expressing emotions in the self and others, b) regulating emotion in the self and others and c) using emotions in adaptive ways. Although these processes are common to everyone, the given model also addresses individual differences in processing styles and abilities (Salovey \& Mayer, 1990).

\subsection{Dimensions of Emotional Intelligence}

Among all of the EI models developed so far, the Goleman's (2001) refined model appears to be the most prominent. Boyatzis et el., (2000) refined Goleman's, 1998a emotional intelligence model from five dimensions (self-awareness, self-regulation, motivation, empathy and social skills) down to four (self-awareness, self-management, social awareness and relationship management), to capture the full scope of emotional competencies. This has become a commonly used model of emotional intelligence. These four domains are shared by all the main variations of EI theory, although other researchers might use different terms to refer the same thing. The authors had forward features domains of EI by using a chart to encapsulate this perspective.

\subsubsection{Personal Competence}

- Self-awareness is supported by the ability to read one's emotions and recognize their impact. It involves accurate self-assessment that allows cognizance of one's strengths and limits, as well as self-confidence.

- Self-management draws from competencies of emotional self-control, transparency, adapt ability, achievement, initiative, and optimism.

\subsubsection{Social Competence}

- Social awareness is supported by empathy, organizational awareness that enables the leader to discern the relationships and politics of the organization, and service that meets the needs of those connected to the organization. 
- Relationship management requires developed skills in inspirational leadership to motivate, influence that allows for persuasion, developing others through feedback and guidance, change catalyst, conflict management, building bonds that cultivate and maintain relationships, and teamwork and collaboration that support cooperation and team building.

\section{CONCEPTUAL FraMEWORK}

In the current research study the variable of leader's emotional intelligence is taken as the independent variable while employees' retention intention is taken as the dependent variable. Further, in order to assess the relationship between these two variables, following figure 1 conceptual framework has illustrated while assuming that other facts are remaining constant.

Independent Variable

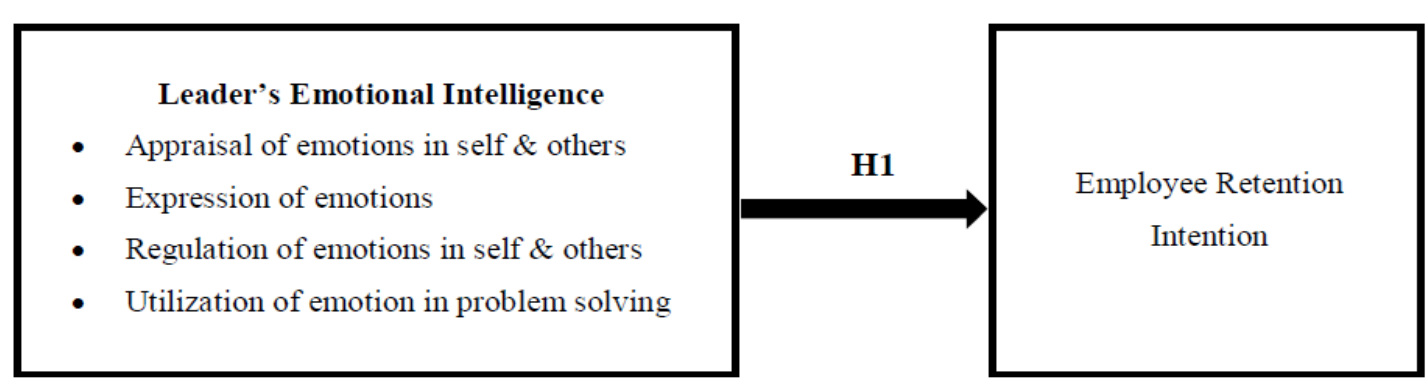

Figure1: Conceptual Framework of the Study

Source: Author, 2018

\subsection{Development of Hypotheses}

Based on the above literature support and considering the descriptive review of literature the current study has hypothesized that the more emotionally intelligent amanager was (as rated by their direct reports), the more likely their staff would be to retain longer with the organization. Thus the following hypothesis has advanced by the researcher to be tested with empirical data collected from employees in a well-worn company in Sri Lankan. Moreover the hypothesis formed as,

H1a $=$ There is a significant relationship between the leaders' emotional intelligence and employee retention intention.

H1b $=$ There is a significant impact of leaders' emotional intelligence to the employee retention intention.

\subsection{Overall Research Design}

As the current research attempts to establish a causal relationship between variables by testing the formulated hypothesis, it would be considered as an explanatory research. In particular, the researcher wanted to explain the extent to which the organizational leaders' emotionally intelligent behavior had influenced upon its employees' retention intention. Hence the research work is launched as an explanatory study since it emphasis on getting a clearer view of the relationship.

There is no any straightforward academic demonstration carried out in order to investigate the relationship between these two variables in Sri Lankan context though it was indirectly well explained ample of studies conducted in foreign contexts. Therefore it is important to test the relationship between this both variables relating to a sample taken by the Sri Lankan workforce.

A survey strategy has been used with deductive approach to the current research as it allows having collection of a large amount of data from a sizeable population in a highly economical way. According to Malhotra and Birks (2003) quantitative research is suitable for measuring both attitudes and behavior. Therefore the current study is also carried out as a quantitative research work. Further it has utilized descriptive statistical techniques such as mean, mode, variation and standard variation. Specifically the data was subjected to statistical tests such as correlation and regression to ensure the most validated determinants.

A structured questionnaire is used as the data collection technique since it's a quantitative study that deals with numerical data. It is probable a cross-sectional study as it focuses on describe a particular phenomenon at a particular time. 
Questionnaires are distributed to sample of 62 employees among the head office staff of the selected company. Stratified random sampling is preferred for deciding sampling technique since the population is included with both executive and non-executive staff. Therefore the sampling frame is divided into two subsets and a random sample is then drawn from each of the strata. A standardized questionnaire is occupied for data collection purposes but with some modifications to the original scheme, after doing the validation test.

Unit of analysis taken for the current study is the "individual employee from the head office staff who is currently working for E B Creasy and Company PLC".

\subsection{Population}

The target population for this study consisted with the head office staff of EBC; which is a wellestablished organization in Sri Lanka since 1878 with 100-300 on site employees. Of that 300, approximately 150 were belongs to the head office staff located in Colombo 10. Hence the total population for the current study is 150 of employees at EBC head office. This target workforce is included with executives and non-executives across all functions covering up their all business sectors.

\subsection{Sample and Sampling Technique}

The sample for this study included all the executive and nonexecutive employees of head office staff with a total of 150 participants approximately. Of the 75 questionnaires distributed 66 employees responded, giving an 88 percent response rate. Of the returned questionnaires 4 were excluded from the analysis because of incomplete pages. Therefore the remaining valid sample of 62 responses was used for the analysis. For effective coverage of the population stratified random sampling technique was used to select respondents to the sample. Here it was divided the population into two categories as executives and non-executives in order to make the sample is more likely to be representative, as it can ensure that each of the category is represented proportionally within the selected sample.

\section{Data Analysis And Presentation}

\subsection{Testing of Hypotheses}

During the current research project the author used a structured questionnaire which was designed in a way to empirically test the hypotheses developed previously, based on the existing measurement scales in the literature which are already tested and validated widely by various researchers in the domain of EI and employee retention. The researcher has used the Schutte Self Report Emotional Intelligence Test (SSEIT) to assess EI of leaders. This is developed by Schutte, et al., (1998) and focuses on measuring the four aspects of emotional intelligence as defined by Salovey \& Mayer (1990). The questionnaire was converted into a form of which the subordinates are able to rate their leader's level of emotional intelligence as how they perceived it or how they actually feel it. Further, correlation and regression models were used to test the advanced hypotheses and to draw conclusions.

\subsection{Sample Composition}

The final data set that was used for statistical analysis was made up with a total sample of 62 questionnaires including both executive and non-executive employees. The study initially sought to ascertain the general information on the respondents involved in the study with regards to the number year of they worked, age, employment grade and gender. The demographic information points at the respondents' suitability in answering the questions and it also much useful to develop the overall picture of the respondents from which the data were gathered. According to the calculations done, the study recorded a higher response rate from males, with a majority of 54.8\% and $45.2 \%$ of female employees in the selected sample. The results of the gender analysis indicates other than the modern organizations, outmoded organizations originated from long ago in Sri Lanka are still continuing to be dominated by males. According to that statistical table figure 4.1 showed the summary of the total results. The findings indicate that majority (32.3\%) of the sample were aged between 26 and 35 . Therewith $29 \%$ of employees belong to the age group of between 36 and 45 . Yet $21 \%$ of the respondents are 46 to 56 years old. Further, age below 26 respondents are $12.9 \%$ and there were 3 employees who were at the age of above 56. When considering the above facts and figures it implies that the EBC head office staff is consisted with a majority of matured and ripe people rather than a 
young crowd. When looking at the length of service years of employees it reflects with different seniority levels, forming a good proportion of the population. When analyzing their seniority or organizational experience it could be identified that most of respondents have been joined the company within last the 5 years, indicating a $32.3 \%$ of the sample. There were $16.1 \%$ with working experience of more than 5 years, but not beyond 10 years. According to the frequency rates it would display a diminishing pattern of the total number of employees when moving to upper numbers of service years. There is $30.7 \%$ of employees with more than 20 years of service to the current organization indicating that the retention rate is not much bad at the moment.

\subsection{Validity \& Reliability}

Construct validity of the questionnaire was tested by using factor analysis while the content validity of the current research study was ensured by the conceptualization and operationalization of the variables based on the previous literature. The Kaiser-Meyer-Olkin (KMO) is the measure of sampling adequacy. In here the KMO values for both variables' measurements produced with values closer to 1, which indicates that the sample is adequate and researcher can proceed with the Factor Analysis. Therewith the Bartlett's Test of Sphericity is the test for null hypothesis. Taking a 95\% level of significance both the p-values (Sig.) are less than 0.05 .

One of the famous method for analyze internal reliability or used to get the inter item consistency is Cronbach"s Alpha test. The Cronbach's alpha coefficient was calculated for aggregate sample of 62 respondents and it would able to gain a value of .922 as Cronbach's alpha for the twenty six items of leaders' EI and .766 of a Cronbach's alpha value for the eight items in employee retention intention. Since each variable or for each instrument was gained values above 0.7 it can be concluded that the internal reliability of the instrument is satisfactory.

\subsection{Testing of Hypotheses}

Methodology of Pearson's correlation coefficient was used to analyse the relationship and to quantify the strength of relationship between the variables. Thereafter through simple regression analysis researcher try summarize how far the independent variable affects to the dependent variable.

H1a $=$ There is a significant relationship between the leaders' emotional intelligence and employee retention intention.

Table1: Result of Correlation Analysis of the Leaders' Emotional Intelligence and Employees' Retention Intention

\begin{tabular}{|l|l|l|l|}
\hline \multicolumn{2}{|c|}{ Correlations } \\
\hline \multirow{2}{|c|}{} & $\begin{array}{l}\text { Leaders' Emotional } \\
\text { Intelligence }\end{array}$ & $\begin{array}{l}\text { Employees' } \\
\text { Intention }\end{array}$ \\
\hline \multirow{3}{*}{ Leaders' Emotiontion } \\
& Pearson Correlation & 1 & $.571^{* * *}$ \\
\cline { 2 - 4 } & Sig. (2-tailed) & & .000 \\
\cline { 2 - 4 } & $\mathrm{N}$ & 62 & 62 \\
\hline \multirow{3}{*}{ Employees' Retention Intention } & Pearson Correlation & $.571^{* *}$ & 1 \\
\cline { 2 - 4 } & Sig. (2-tailed) & .000 & 62 \\
\cline { 2 - 3 } & $\mathrm{N}$ & 62 & \\
\hline$* *$ Correlation is significant at the 0.01 level (2-tailed). \\
\hline
\end{tabular}

\section{Source: Survey Data, 2018}

According to the table 1Pearson Correlation is positive 0.571researcher can conclude that when the level of leaders' EI increase, the employees' retention intention also increases, means there is a positive relationship between the variables. The Sig. (2-tailed) value represents 0.000 which is less than the base line value (0.01). Therefore we can statistically accept the alternative hypothesis by rejecting the null hypothesis and can conclude that there is a statistically significant linear relationship between the level of leaders' EI and the employees' retention intention. Further the magnitude or strength of the association is approximately moderate since the Pearson Correlation value is closer to 0.5 . So, there is statistical evidence to claim that there is a moderately positive relationship between leaders' EI and employee retention intention. Therefore, H1 a hypothesis can be accepted.

H1b = There is a significant impact of leaders' emotional intelligence to the employee retention intention. 
Emotional Intelligence and Employee Intention to Retain: A Case Study of a Organization in Fast Moving Consumer Goods in Sri Lanka

Table2: Result of Simple Regression Analysis

\begin{tabular}{|l|l|l|l|l|}
\hline \multicolumn{5}{|c|}{ Model Summary } \\
\hline Model & R & R Square & Adjusted R Square & Std. Error of the Estimate \\
\hline 1 & $.571^{\mathrm{a}}$ & .325 & .314 & .50136 \\
\hline a. Predictors: (Constant), Leaders' Emotional Intelligence \\
\hline
\end{tabular}

Source: Survey Data, 2018

According to the above table 2 , $\mathrm{R}$ square is 0.325 , which implies the variance in employees' retention intention, is explained by the independent variable of their leaders' EI. Further the independent variable that was studied explains only $32.5 \%$ of the employee retention intention as represented by the R square. This therefore means that other factors which are not studied in this research contribute $67.5 \%$ to the employees' retention intention. Therefore, further research should be conducted to investigate the other factors that affect employee retention intention.

Table3: ANOVA Table of Regression

\begin{tabular}{|l|l|l|l|l|l|l|}
\hline \multicolumn{7}{|l|}{ ANOVA $^{\mathrm{a}}$} \\
\hline \multicolumn{2}{|l|}{ Model } & Sum of Squares & df & Mean Square & F & Sig. \\
\hline \multirow{3}{*}{1} & Regression & 7.277 & 1 & 7.277 & 28.951 & $.000^{\mathrm{b}}$ \\
\cline { 2 - 7 } & Residual & 15.082 & 60 & .251 & & \\
\cline { 2 - 6 } & Total & 22.359 & 61 & & & \\
\hline
\end{tabular}

Source: Survey Data, 2018

This Anova table reports how well the regression equation fits the data. Considering the Sig. value of above table 3, it indicates the statistical significance of the regression model that was run before. Here the Sig. value is 0.000 , which is less than 0.05 , and it indicates that overall the regression model statistically significantly predicts the outcome variable or simply it means to be accepted the R square statically. According to the above explanations the leaders' emotional intelligence has a significant moderately positive impact on employee retention intention. Thus, hypothesis two (H1b) also accepted based on the above mentioned evidence.

\subsection{Regression Equation}

$$
Y=m X+c
$$

Employee Retention Intention $=1.188+0.571$ Leaders' Emotional Intelligence

Where;

$\mathrm{Y}=$ Employee Retention Intention and $\mathrm{X}=$ Leaders' Emotional Intelligence

In determining the effectiveness of improving the organizational leaders' EI to retain employees, the study further intends to develop the regression equation using regression analysis results in order to determine the nature of relationship between the variables.

According to the regression equation established, taking all factors into account and leaders' EI is at zero, employee retention intention will be 1.188 . The data findings analyzed also shows that taking all other independent variables at zero, a unit increase in leaders' EI will lead to a 0.571 increase in employees' retention intention. This supposes that leaders' EI contribute most to the employees' retention intention. At 5\% level of significance and 95\% level of confidence, leaders' EI was a significant factor in predicting the employee retention within an organization.

\section{FINDINGS}

As usual the sums and average rates of participant's responses to the employee retention and leaders EI questions were calculated. According to the corresponding percentages of employees associated with each of the four levels of retention it can be observed that, with respect to total retention, 24.2 percent of employees have a high retention intention, 56.5 per cent have a moderate intention to retain, 17.7 per cent do not have an intention to retain and 1.6 per cent have none of intention to retain. The percentage of employees who were having an intention to retain in this sample is 
considerably higher (total of $80.7 \%$ ). While considering the average values of leaders EI, $21 \%$ of employees have rated as their leaders are having high EI. 69.4\% of employees have rated as their leaders are having satisfied level of EI and $9.7 \%$ of employees are not satisfied about their leaders EI level.

As it was described in the above sections, the leaders' EI was found to correlate positively with total retention intention at 0.571 . Thus, 32.5 per cent of the variability in employees' retention intention scores was accounted for by direct report rated manager EI. Thus, the hypothesis was accepted that there is a significant relationship and also a moderately positive impact from leaders' EI (as rated by their direct reports) to the employees' retention intention.

Indeed this research is confirming that one person's definition of an effective boss could be someone else's worst nightmare (Palmer \& Gignac, 2012). According the literature it reveals that a manager's EI may be an underlying attribute that helps them both to identify individual drivers of engagement or the reasons for retention. So EI is necessary for a leader to identify the relevant leadership style that works best for an individual and, subsequently, adopt that leadership style in management of them. Indeed, previously, we have shown that up to $57.1 \%$ of an individual's retention score can be accounted for by the "fit" between desired and experienced leadership. That is the employees are working for a boss who demonstrates the type of leadership style which the employees are more prefer or which is motivated them to retain. Complementing a company wide an EI development program for managers may equip managers to better identify and facilitate with the most suitable leadership style at an individual level.

\subsection{Implications}

Today employee retention has become an important strategic aspect for each and every organization due to the increasing competition. To manage and to retain top talent it requires a constant balance between the human desires and the strategic and financial needs of the business. Therefore this research finding would be much useful to those who are challenged with the task of improving employee engagement for the purpose of enhancing talent retention basically. When the employees are well engaged with their job and the organization they willingly perform beyond what is expected of them and not intending to quit even when the conditions in which they work become difficult. Indeed the findings of this investigation suggest that engagement and its outcomes might increase from increasing the EI of an organization's management.

According to Goleman's model managers those with higher EI are considered to be self-aware which means they are conscious of the impact they can have on others. And also empathetic which means they can accurately perceive and understand the feelings of others and demonstrate this understanding to others. Moreover they can effectively regulate and manage their own emotions and also can positively influence the feelings of others. So such array of a behavior is really important for a leader since they should be a role model with appropriate behavior in most times. Therefore more emotionally intelligent a manager was as perceived by their direct reports; the more likely their staff would be to demonstrate the value creating behaviors that define as employee engagement. Hence the study finding further implies to the organizations, in order to inculcate that adherence feeling within the staff towards their organization, first the leaders should be a role model to the other by displaying appropriate behaviors. In that case the organizations should be more concentrate on increasing the EI of the organization's leaders.

The current study would have implication not only for the organizations but also into our personal life too. By understanding your emotions and how to control them, you're better able to express how you feel and understand how others are feeling. This allows you to communicate more effectively and forge stronger relationships, both at work and in your personal life. Therefore by improving EI you would be able to retain your loved ones with you for a longer period of time. You would be able to maintain effective relationships at your workplace without getting worried or being break up due to tiny issues or misunderstandings. 


\section{CONCLUSiON}

In this research paper it was aimed to present the findings of a study examining the relationship between the EI of managers and levels of employee retention intention amongst their staff involved with one of the leading organizations in fast moving consumer goods (FMCG) industry.

The major conclusion of this study was that there's a moderately positive relationship between the leaders' EI and employee retention intention. Since the correlation between variables is moderately positive it implies that there may be some other factors or reasons that would impact the employees' retention intention more intensely. However it would be much essential for organizations to pay their attention to this aspect too, since they would definitely get an added advantage by improving EI of not only within leaders but also within the whole staff. Finally based on the all the evidence stated and statistical explanations both hypotheses were accepted by rejecting the null hypotheses.

Finally through the survey investigation the researcher was able to find that the EI of managers or organizational leaders has a meaningfully correlation with employees' retention intention. This information may prove useful to those who are challenged with the task of improving employee retention and organizational performance more broadly. The findings of the research may also prove useful to those who are passionate about developing the EI of managers but find it difficult to convince budget decision makers of the value this can create.

Most people tend to think that retention of employees is a part of human resource management and planning efforts. Turnover, as the opposite of retention, often has been seen as a routine HR matter requiring records and reports. Indeed, retention of employee is not a matter that can be dealt by the reports or records, it is purely depends on how we understand individual concerns and we react towards them. Nonetheless, the results of this study suggest that a manager's EI has a positive influence on the retention intention of their staff and that improving the EI of management within an organization may have a positive impact on its performance and its capacity to retain talent.

\section{RECOMMENDATIONS}

As a manager or a leader it is must that to have a proper understanding about the personality of each of their team member and that of their own as well. With that they would be able to form better teams for certain tasks. By being emotionally intelligent the leaders can figure out who is under stress during work and how to relieve that stress so they can perform better. Therefore the study recommends to get necessary actions to improve the EI of leaders, not only for the purpose of retaining employees but also to get a better outcome from them.

Basically the researcher would provide two options for organizations to increase the EI of its management in two prominent ways. First, by hiring and promoting people into management rolls those are with high EI and secondly by improving the EI of managers through a learning and development intervention. In fact we suggest the organizations, when it comes to gauging job candidates especially into supervisory and managerial positions they can view emotional intelligence as being as important as other qualifications or abilities and also can use EI testing before hiring. Selecting managers who have high EI would definitely have a positive impact on the extent to which an organization succeeds in retaining its most critical workforce as the study reflects.

In previous investigations, it has been demonstrated that the frequency with which managers demonstrate emotionally intelligent workplace behaviors can be increased by on average 10-20 per cent (Gignac, Harmer, Jennings, \& Palme, 2007). Both Mayer and Salovey (1997) and Goleman (1998) have noted that EI is potentially incremental skill or ability and can be developed through training and experience. Therefore it is recommended to the organizations to take necessary steps in this regard to improve EI. They can implement the awareness programms on EI to the whole staff rather than involving the leaders only.

These interventions should be typically involved with a mixture of pre and post intervention 360degree assessments in order to create insights into how often EI behaviors are being displayed by participants (by the leaders specially) in pre and post interventions. Further it is suggest implementing workshop sessions where participants could practice applying techniques to improve their EI and also individual coaching sessions to deepen the learning and insight with regard to EI. 


\section{LIMITATIONS}

The sample of this study was consisted with 62 employees who work in the systemically one of the leading organization in the field of FMCG Sri Lanka. The sample was limited only to that small context. The other organizations in the field of FMCG were not considered due to the limited time frame and because of the practical difficulty of collecting the data from all organizations. The generalizing the result was the main limitation for the current research study.

Many research articles conducted under the topic if EI tend to mentioned one of their limitation as, it was relying on self-reported data since it could occur a self-biasness when people evaluating them by their own self. However in the current study researcher was able to overcome that limitation by providing opportunity to evaluate the managers' actual level of EI from the employees' point of view since they are the ones who work under the manager. Thereafter another limitation was occurred because the level of self-awareness and self-management competencies of the manager were difficult to be evaluated by the employees because the managers are the judges of their own personal competencies.

\section{REFERENCES}

[1] Beardwell, I., Holden, L., \& Claydon, T. (2007). In Human resources management a contemporary approach (p. 4th Edition). London: Prentice Hall.

[2] Carmeli, A. (2003). The relationship between Emotional Intelligence and work attitudes, behavior \& outcomes, An examination among senior managers. Journal of Managerial Psychology, 18 (8), 788-813.

[3] Caruso, D. R., Mayer, J. D., \& Salovey, P. (2002). Emotional intelligence and emotional leadership. (R. E. Riggio, S. E. Murphy, \& F. J. Pirozzolo, Eds.) Multiple Intelligences and Leadership, 55-74.

[4] Chitra, K. (2013). Role of leaders in employee retention - a pragmatic study with reference to private sector bank employees. International Research Journal of Business and Management, 6: pp.65-74.

[5] Daily FT. (2018, November 19). Emotionally intelligent leaders: A rare breed in Sri Lanka? (C. @. Ltd., Trans.) Retrieved from Daily FT e-Paper: http://www.ft.lk/columns/emotionally-intelligent-leaders-a-rarebreed-in-sri-lanka/4-597130

[6] Das, B. L., \& Baruah, D. (2013). Employee Retention: A Review of Literature. Journal of Business and Management, 2319-7668. Volume 14, Issue 2.

[7] Das, B., \& Baruah, M. (2013). Employee Retention: A Review of Literature. Journal of Business and Management.

[8] Expedite, Human Resources. (n.d.). THE IMPORTANCE OF EMOTIONAL INTELLIGENCE IN BUSINESS. Retrieved from Expedite Business Development Consulting Human Resource: https://expedite-consulting.com/the-importance-of-emotional-intelligence-in-business/

[9] Gignac, G., Harmer, R., Jennings, S., \& Palme. (2007). EI training and sales performance. Cross Cultural Management: An International Journal.

[10] Goleman, D. (1995). Emotional Intelligence. New York, NY: Bantam Books.

[11] Goleman, D., Boyatzis, R., \& Mckee, A. (2004). Learning to lead with Emotional Intelligence. Primal Leadership.

[12] Kim, S., Price, J. L., Mueller, C. W., \& Watson, T. W. (1996). The determinants of career intent among physicians at a U.S. Air Force hospital. Human Relations, 49(7): 947-976.

[13] Michael, S. O. (2008). motivational strategy as penance for employee retention and turnover in selected private and public sector in cape pronvince. SA.

[14] Palmer, B. R., \& Gignac, G. (2012). The impact of emotionally intelligent. INDUSTRIAL AND COMMERCIAL TRAINING, 1, 9-18.

[15] Salovey, P., \& Mayer, J. D. (1990). Emotional intelligence. Imagination, Cognition, and Personality. 9, 185-211.

[16] Salovey, P., \& Mayer, J. D. (2004). Emotional intelligence. (P. Salovey, M. A. Brackett, \& J. D. Mayer, Eds.) Key Readings on the Mayer and Salovey Model, 29-59.

[17] Schutte, N., Malouff, J., Hall, L., Haggerty, D., Cooper, J., Golden, C., . . . Dornheim, L. (1998). Development and validation of a measure of emotional intelligence. Personalitya nd Individual Differences, 1 67-177.

[18] Tett, R. P., \& Meyer, J. P. (1993). Job satisfaction, organizational commitment, turnoverintention, and turnover: Path analyses based on meta-analytic findings. Personnel Psychology, 2(46), 259-293. 
Emotional Intelligence and Employee Intention to Retain: A Case Study of a Organization in Fast Moving Consumer Goods in Sri Lanka

[19] Vecchio, R. P. (1985). Predicting employee turnover from leader-member exchange. A failure to replicate. Academy of Management Journal, 28(2) 478-485.

[20] Yukl, G. (2002). Leadership in Organizations (5th ed.). Upper Saddle River, NJ: Prentice Hall.

Citation: P.A.S. Fernando, Prof. Prasadiniu Gamage. "Emotional Intelligence and Employee Intention to Retain: A Case Study of a Organization in Fast Moving Consumer Goods in Sri Lanka" International Journal of Managerial Studies and Research (IJMSR), vol 7, no. 8, 2019, pp. 13-25. doi: http://dx.doi.org/10.20431/ 2349-0349.0708002.

Copyright: (C) 2019 Authors. This is an open-access article distributed under the terms of the Creative Commons Attribution License, which permits unrestricted use, distribution, and reproduction in any medium, provided the original author and source are credited. 